\title{
Effective Corrosion Protection Coatings of Polyaniline/Gamma-Alumina Nanocomposites
}

\author{
Yuan-Fu Yu, Parthiban Venkatesan, ${ }^{1}$ and Kuo-Yi Huang ${ }^{2 *}$ \\ Department of Mechatronic Engineering, Huafan University, \\ No. 1, Huafan Rd., Shihding Dist., New Taipei City 223, Taiwan \\ ${ }^{1}$ Department of Chemistry, National Chung Hsing University, \\ 145 Xingda Rd., South Dist., Taichung City 402, Taiwan \\ ${ }^{2}$ Department of Bio-Industrial Mechatronics Engineering, National Chung Hsing University, \\ 145 Xingda Rd., South Dist., Taichung City 402, Taiwan \\ (Received April 20, 2017; accepted July 27, 2017)
}

Keywords: corrosion, nanocomposite, polyaniline, gamma alumina, ac impedance

In this research, we present the first successful preparation of polyaniline/gamma-alumina nanocomposites towards their use in anticorrosive coatings. Polyaniline/gamma-alumina nanocomposites have been successfully synthesized via in situ ultrasonic dispersion and oxidative polymerization, and then characterized by Fourier transform infrared (FTIR) spectroscopy, X-ray diffraction (XRD), and transmission electron microscopy (TEM). The coatings of polyaniline/ gamma-alumina nanocomposites on a cold-reduced carbon steel sheet were found to provide greatly superior corrosion protection compared with pure polyaniline, through a series of electrochemical measurements in $5 \mathrm{wt} \%$ aqueous $\mathrm{NaCl}$ electrolyte. As the loading of gamma alumina increased, the corrosion potential became less negative, the polarization resistance increased, and the corrosion current decreased, indicating that the anticorrosion properties were improved. By electrochemical impedance spectroscopy (EIS) analyses, the results of Nyquist plots were fitted using an equivalent circuit, which presents two characteristic semicircles with marked increases in the pore resistance $\left(R_{\text {pore }}\right)$ and charge transfer resistance $\left(R_{t}\right)$ of nanocomposites along with the loading of gamma alumina. Bode plots also showed a great increase in impedance for the coatings with the loading of gamma alumina. The effect of the corrosion inhibition of the nanocomposite coating was also evidenced by scanning electron microscopy (SEM) after the corrosion test.

\section{Introduction}

Polyaniline (PANI) has been an attractive polymer for material scientists and related researchers since the discovery of conductive polymers. ${ }^{(1,2)}$ Its area of application is wide and still growing, e.g., photoelectronic devices, ${ }^{(3)}$ electrochromic devices, ${ }^{(4)}$ organic solar cells, ${ }^{(5)}$ fuel cells, ${ }^{(6)}$ sensors, ${ }^{(7)}$ electromagnetic shielding materials, ${ }^{(8)}$ gas separation membranes, ${ }^{(9)}$ and anticorrosion coatings. ${ }^{(10-14)}$ It has been demonstrated that organic conjugated PANI has excellent anticorrosive properties promising for use as an anticorrosive coating to replace chromium coatings, which are an environmental concern. The mechanism of corrosion protection by PANI is related to both barrier

${ }^{*}$ Corresponding author: e-mail: kuoyi@dragon.nchu.edu.tw http://dx.doi.org/10.18494/SAM.2017.1662 
and electrochemical protection effects, whereby increases in corrosion potential and passivation layer formation lead to an effective corrosion rate reduction on metal surfaces. ${ }^{(10-17)}$

Recently, a considerable number of publications associated with polymer-clay or polymer-silica nanocomposites have been reported regarding effectively improved anticorrosive properties. It has been shown that montmorillonite clay and nanosilica can enhance the anticorrosive effect of polymer coatings, owing to the enhancement of barrier properties by increasing the lengths of diffusion pathways for oxygen and water. ${ }^{(18-28)}$ However, most of the anticorrosive nanocomposite coatings were prepared by incorporating layered montmorillonite clay or nanosilica and should have suitable organo-intercalating or silane-coupling agents to enhance the compatibility between the dispersed phase of inorganic particles and various polymer matrixes. Although there are various organic-inorganic hybrid materials exhibiting excellent corrosion protection, simpler processes or materials for the preparation of nanocomposite coatings are worth developing for mass production.

Commercial nanoscale gamma alumina with a particle size smaller than $20 \mathrm{~nm}$ has attracted our attention in developing a new series of nanocomposite coatings for anticorrosive applications. The high surface area of nanoscale gamma alumina is considered to have an effective interphase strength between nanoparticles and a polymer matrix. In addition, the low density and high volume of nanoscale gamma alumina could be advantageous in handling the nanomaterials in the preparation process when low load is applied to the polymer matrix. Furthermore, the electrical insulation of gamma alumina, as well as the improvement of barrier properties by the dispersed nanoparticles are thought to improve the corrosion potential and resistance on metal surfaces. Having the advantages of high specific surface area and low cost, new applications of polymer/ gamma alumina nanocomposites in coating or membrane science are expected. It was previously reported that the highly dispersed nanoalumina could be prepared only by ultrasonic treatment for the preparation of $\mathrm{Al}_{2} \mathrm{O}_{3}$ /polymide (PI) hybrid films. ${ }^{(29)}$ Interestingly, Zhang ${ }^{(30)}$ demonstrated that the corrosion protection of the epoxy coating was greatly enhanced by using alumina-PANI particles as fillers; however, no detailed electrochemical study could be referenced.

In this work, we present the first evaluation of the effect of nanocrystalline gamma alumina on corrosion protection, by a simple ultrasonic dispersion process. A series of PANI/gamma-alumina (PANI-AlO) nanocomposites were synthesized by the in situ ultrasonic dispersion of nanoscale gamma alumina followed by the oxidative polymerization of the aniline monomer in an acidic aqueous medium. The as-prepared PANI-AlO nanocomposites were characterized by attenuated total reflectance Fourier transform infrared (ATR-FTIR) spectroscopy, wide-angle powder X-ray diffraction (XRD) analysis, and high-resolution transmission electron microscopy (HR-TEM). Subsequently, the as-prepared PANI-A1O nanocomposites were further investigated by a series of electrochemical analyses such as open-circuit potential (OCP), Tafel plot, and ac impedance measurements in $5 \% \mathrm{NaCl}$ electrolyte. The surfaces of cold-reduced carbon steel sheets with and without nanocomposite material coatings were compared by scanning electron microscopy (SEM). The protection mechanism of PANI-AlO nanocomposite anticorrosive coatings was also discussed.

\section{Materials and Methods}

Aniline ( $>98 \%$, Fluka) was distilled prior to use. Ammonium peroxodisulfate (MERCK), hydrochloric acid (37\%, Riedel-de Haën), ammonia solution (25\%, Riedel-de Haën), nanoalumina (UniRegion Bio-Tech), and $N$-methyl-2-pyrrolidone (NMP, Mallinckrodt) were used as received 
without further purification. All the reagents were reagent grade unless otherwise stated. Attenuated total reflectance FTIR was obtained with an FTIR spectrometer (JASCO FTIR-4100) at room temperature. A wide-angle powder XRD study of the samples was carried out using a Rigaku D/MAX-3C OD-2988N XRD instrument with a copper target and a Ni filter at a scanning rate of $4 \% \mathrm{~min}$. The nanoscale structure of nanocomposites was investigated by HR-TEM (JEM2100 , JEOL), operated at an acceleration voltage of $200 \mathrm{kV}$. The ultrathin sample with a thickness of $100 \mathrm{~nm}$ was prepared at $20^{\circ} \mathrm{C}$ using an ultramicrotome (Ultracut UCT, Leica). Electrochemical measurements were performed using a CHI 614C Electrochemical Analyzer ( $\mathrm{CH}$ Instruments) with a conventional three-electrode system. The surface morphologies of a steel plate cold-rolled commercial grade (SPCC) after the corrosion test were characterized by SEM analyses using a Topcon SM-350 model.

\subsection{Synthesis of PANI and PANI-AIO nanocomposites}

The compositions of PANI-A1O nanocomposites prepared in this study are listed in Table 1. As the typical procedure for the preparation of PANI and PANI-AlO nanocomposites via in situ oxidation polymerization, an appropriate amount of nanoscale gamma alumina was introduced into $200 \mathrm{~mL}$ of $1 \mathrm{~N}$ hydrochloric acid and ultrasonic dispersion for $24 \mathrm{~h}$ in a closed system. The aniline monomer was subsequently added to the solution of dispersed gamma alumina and magnetically stirred for $30 \mathrm{~min}$ under an ice-bath cooling condition. A separate solution containing an appropriate amount of ammonium peroxodisulfate was dissolved in $20 \mathrm{~mL}$ deionized water and used as an oxidant for polymerization. The ammonium peroxodisulfate solution was added into the aniline monomer solution drop by drop in an ice bath and magnetically stirred for $30 \mathrm{~min}$. The solution gradually turned deep blue. Then, the ice bath was removed and the solution was further stirred for $30 \mathrm{~min}$ at room temperature. During this period, a deep green solution containing suspended particles was formed. Green particles were collected through suction filtering and subsequently added to with the prepared $200 \mathrm{~mL}$ of $1 \mathrm{~N}$ ammonia solution. The solution turned deep blue immediately and then was magnetically stirred for $1 \mathrm{~h}$. The deep blue products were then collected by suction filtering, washed with deionized water, and dried at $50{ }^{\circ} \mathrm{C}$ for $48 \mathrm{~h}$. The as-prepared PANI and PANI-AlO nanocomposites were then gound into fine powder and collected for further use (yield: $\sim 20 \%$ ).

Table 1

Composition of PANI-AlO nanocomposites prepared by in situ polymerization and their corrosion protection properties and parameters obtained by simulation of the impedance curves using electrochemical corrosion measurements.

\begin{tabular}{|c|c|c|c|c|c|c|c|c|c|c|c|c|}
\hline \multirow{2}{*}{$\begin{array}{l}\text { Compound } \\
\text { code }\end{array}$} & \multicolumn{2}{|c|}{$\begin{array}{c}\text { Feed composition } \\
(\mathrm{wt} \%)\end{array}$} & \multicolumn{6}{|c|}{ Electrochemical corrosion measurements ${ }^{\mathrm{a}}$} & \multicolumn{4}{|c|}{$\begin{array}{l}\text { Parameters of } \\
\text { quivalent circuit }\end{array}$} \\
\hline & Aniline & $\begin{array}{l}\text { Gamma- } \\
\text { alumina }\end{array}$ & $\begin{array}{l}E_{\text {corr }} \\
\text { (V) }\end{array}$ & $R_{p}(\Omega)$ & $I_{\text {corr }}(\mathrm{A})$ & $P_{E F}(\%)$ & $\begin{array}{c}R_{\text {corr }} \\
\text { (mil/year) }\end{array}$ & $\begin{array}{l}P_{E F} \\
(\%)\end{array}$ & $R_{S}(\mathrm{n} \Omega)$ & $C_{c}(\Omega)$ & $\begin{array}{l}C_{d l} \\
(\mu \mathrm{F})\end{array}$ & $R_{t}(\Omega)$ \\
\hline SPCC & - & - & -0.811 & 9544 & $2.125 \times 10^{-6}$ & 0.9701 & - & 20 & - & - & 8.2 & 18 \\
\hline PANI & 100 & 0 & -0.678 & 35642 & $7.682 \times 10^{-7}$ & 0.3507 & 2.73 & 108 & 25.2 & 122 & 0.6 & 301 \\
\hline PANI-AlO1\% & 99 & 1 & -0.570 & 234290 & $1.712 \times 10^{-7}$ & 0.0782 & 23.55 & 32 & 3.8 & 68564 & 3.9 & 17026 \\
\hline PANI-AlO3\% & 97 & 3 & -0.503 & 290323 & $1.635 \times 10^{-7}$ & 0.0746 & 29.42 & 45 & 4.6 & 142390 & 4.2 & 27849 \\
\hline PANI-AlO5\% & 95 & 5 & -0.433 & 940756 & $5.356 \times 10^{-8}$ & 0.0244 & 97.57 & 24 & 2.8 & 194860 & 0.3 & 79465 \\
\hline
\end{tabular}

${ }^{\text {a }}$ Saturated calomel electrode (SCE) as reference electrode. 


\subsection{Electrochemical corrosion evaluations of as-prepared PANI and PANI-AIO nanocomposites}

To evaluate the electrochemical corrosion performance of PANI-AlO nanocomposites, a cold-reduced carbon steel sheet with commercial specifications, named SPCC, referenced in the Japanese Industrial Standards (JIS) G3141, was used as an electrode. The SPCC electrode was cut to form a mounting electrode having a thickness of $1 \mathrm{~mm}$ and an area of $1 \mathrm{~cm}^{2}$. A series of solutions of PANI and PANI-A1O nanocomposite materials was prepared by dissolving the synthesized powder of PANI and PANI-AlO nanocomposites (e.g., $0.5 \mathrm{~g}$ ) in the solvent NMP (e.g., $40 \mathrm{~g}$ ). After filtering, the solution was coated onto the SPCC electrode, followed by drying in a baking oven at $100{ }^{\circ} \mathrm{C}$ for $24 \mathrm{~h}$ to allow for the evaporation of NMP to give a uniform and dense coating approximately $20 \mu \mathrm{m}$ in thickness, measured using a digimatic micrometer (Mitutoyo, Japan). The coated and uncoated SPCC electrodes were then mounted to the working electrode so that only the coated side of the SPCC electrode was directly in contact with the electrolyte. The working electrode was designed such that the test specimen could be replaced easily. In this study, a flat SPCC electrode was also designed for the evaluation of nanocomposite coatings. This working electrode is generally used for both accuracy improvement and sample specimen replacement during the corrosion test. The working electrode was modified from our previous testing apparatus ${ }^{(25)}$ in which the edges of the coupons were sealed with a superfast epoxy cement, and it was hard to replace the specimen. Herein, the SPCC specimen was mounted and sealed by an o-ring, which is advantageous in replacing samples and improving the accuracy. A threeelectrode system, as illustrated in Fig. 1, with the designed working electrode, a saturated calomel electrode (SCE), and a graphite rod counter electrode was set up in a jacketed cell with $5 \mathrm{wt} \%$ $\mathrm{NaCl}$ aqueous solution as the electrolyte. All the electrochemical corrosion and ac impedance measurements were performed on a $\mathrm{CHI} 614 \mathrm{C}$ electrochemical analyzer of $\mathrm{CH}$ Instruments. The open circuit potential (OCP) was measured to monitor the relationship of potential with time. After a 30 min measurement, the potential curve gradually became stable. The end point of the potential

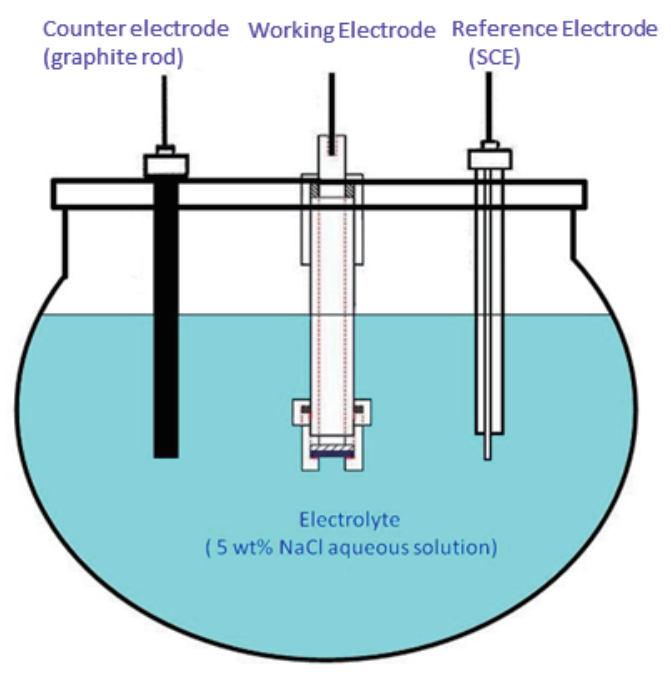

Fig. 1. (Color online) Three-electrode system setup for the electrochemical measurement. 
curve was near the equilibrium state of the system. The equilibrium potential was recorded as the corrosion potential $\left(E_{c o r r}\right)$. The polarization resistance $\left(R_{p}\right)$ was measured by sweeping the applied potential from $20 \mathrm{mV}$ below to $20 \mathrm{mV}$ above $E_{\text {corr }}$ at a scan rate of $10 \mathrm{mV} / \mathrm{min}$ and recording the corresponding current change. $R_{p}$ was obtained from the slope of the potential-current plot. Tafel plots were measured by scanning the potential from $250 \mathrm{mV}$ below and $250 \mathrm{mV}$ above $E_{\text {corr }}$ at a scan rate of $10 \mathrm{mV} / \mathrm{min}$. The corrosion current $\left(I_{\text {corr }}\right)$ was determined by superimposing a straight line along the linear portion of the cathodic or anodic curve and extrapolating it through $E_{\text {corr }}$. The corrosion rate $\left(R_{\text {corr }}\right.$, in milli-inches per year, MPY) was calculated as ${ }^{(22-26)}$

$$
R_{\text {corr }}(\mathrm{MPY})=\left[0.13 I_{\text {corr }}(E . W .)\right] /[A \times d],
$$

where $E . W$. is the equivalent weight (in g/eq.), $A$ is the area $\left(\mathrm{cm}^{2}\right)$, and $d$ is the density $\left(\mathrm{g} / \mathrm{cm}^{3}\right)$.

The ac impedance spectroscopy measurements were carried out in the frequency range of $100 \mathrm{kHz}-0.1 \mathrm{~Hz}$. The working electrode was first maintained in the test environment for $30 \mathrm{~min}$ before the impedance run. This step served to put the electrode in a reproducible initial state and to ensure that no blistering occurred during the conditioning period.

\section{Results and Discussion}

\subsection{Characterization}

The representative ATR-FTIR spectra of gamma alumina, PANI, and PANI-AlO nanocomposite materials are shown in Fig. 2. In the spectra of PANI-A1O3\% and PANI-A1O5\%, the characteristic absorbance bands of PANI and gamma alumina occur in the following assignment: quinoid diimine $v(\mathrm{C}=\mathrm{N}) 1662 \mathrm{~cm}^{-1}$, quinoid ring $v(\mathrm{C}=\mathrm{C}) 1586 \mathrm{~cm}^{-1}$, benzenoid ring $v(\mathrm{C}=\mathrm{C}) 1490 \mathrm{~cm}^{-1}, v(\mathrm{C}-\mathrm{N})$ $1227 \mathrm{~cm}^{-1}$, aromatic $v(\mathrm{C}-\mathrm{H})$ in plane $1158 \mathrm{~cm}^{-1}$, and aromatic out-of-plane bend $v(\mathrm{C}-\mathrm{H}) 815 \mathrm{~cm}^{-1}$. The characteristic vibration bands of gamma alumina were measured at about 761 and $826 \mathrm{~cm}^{-1}$

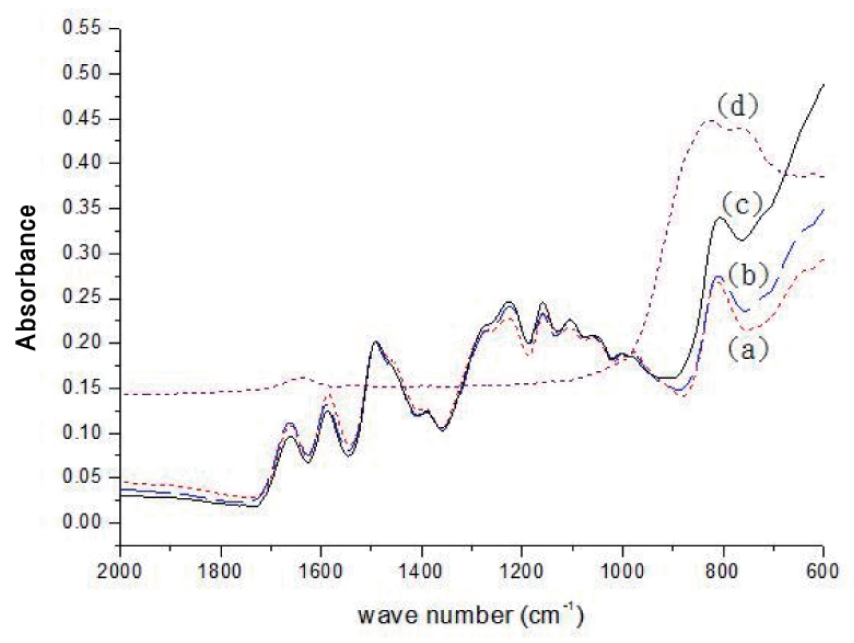

Fig. 2. (Color online) ATR-FTIR spectra of (a) PANI, (b) PANI-AlO3\%, (c) PANI-AlO5\%, and (d) gammaalumina. 
for Al-O stretching. With the loading of gamma alumina, the intensity near the gamma alumina bands increased in the ATR-FTIR spectra.

Wide-angle XRD patterns of gamma alumina, PANI, and PANI-AlO nanocomposite materials were also measured in this study, as shown in Fig. 3. For pure gamma-alumina particles, there are two diffraction peaks at $2 \theta=45.5$ and $66.9^{\circ}$, which correspond to the (400) and (440) planes of gamma alumina. ${ }^{(32)}$ From the results of XRD analyses, all other patterns of as-prepared nanocomposite materials are found to be similar to that of the pure polymer, PANI, with a diffraction $2 \theta$ near $19.2^{\circ}$. The characteristic peaks of gamma alumina cannot be observed. The result may be due to the low load of inorganic particles in the polymer matrix causing the formation of the diffraction peaks of X-rays below the detection threshold.

The real dispersion morphology of nanoscale gamma alumina was evidenced by transmission electron microscopy (TEM), as shown in Fig. 4, revealing $3 \mathrm{wt} \%$ gamma alumina. The image at low magnification was used to determine the dispersion of gamma alumina in the polymer, while the highly magnified image enabled the observation of nanocrystalline gamma alumina. The gray regions in the photograph represent the domain of the PANI matrix and the black or white particles correspond to gamma alumina. The moderate dispersion of nanoparticles in the PANI matrix could be reached only by physical ultrasonic dispersion in the acid phase reaction of PANI polymerization. Although there were some aggregated particles that induced islandlike dispersion, the nanoscale gamma-alumina particles were dispersed all over the matrix of nanocomposite coatings, as determined by low-magnification TEM observation and shown in Figs. 4(a) and 4(b). Therefore, the dispersion of gamma alumina only prepared by the in situ ultrasonic dispersion of nanoscale gamma alumina, without organo-modified silane coupling agents, seems to be a feasible process for the fabrication of anticorrosive coating. The diameter of the primary particles of gamma alumina used in this study is about 9 to $18 \mathrm{~nm}$, as shown in Fig. 4(c). The HR-TEM image illustrates that the periodic array of atoms in gamma-alumina particles with a lattice spacing of 2.3 $\AA$ can be indexed as shown in Fig. 4(d), indicating that the nanoscale gamma alumina used in this study has a crystalline structure.

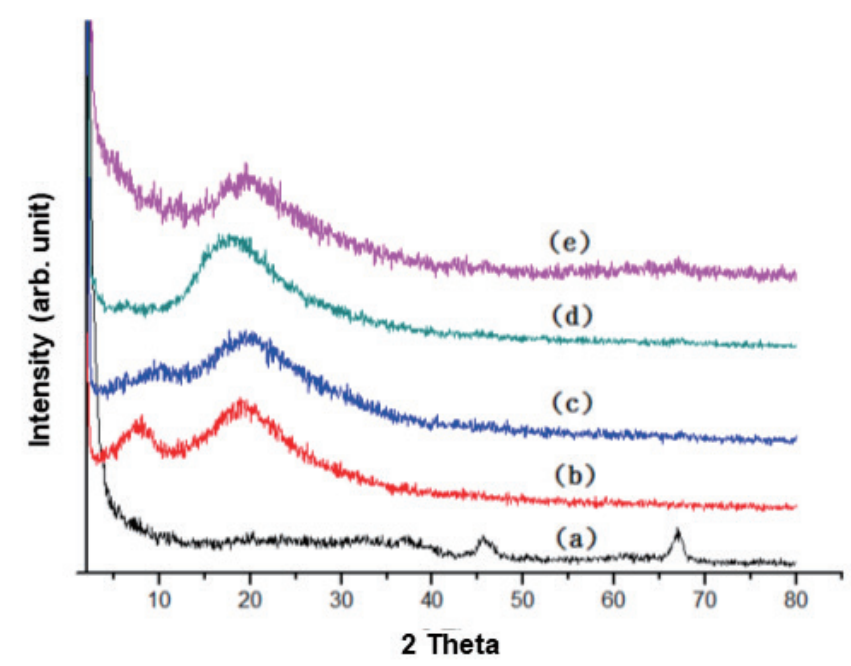

Fig. 3. (Color online) XRD patterns of (a) gamma alumina, (b) PANI, (c) PANI-AlO1\%, (d) PANI-AlO3\%, and (e) PANI-AlO5\%. 


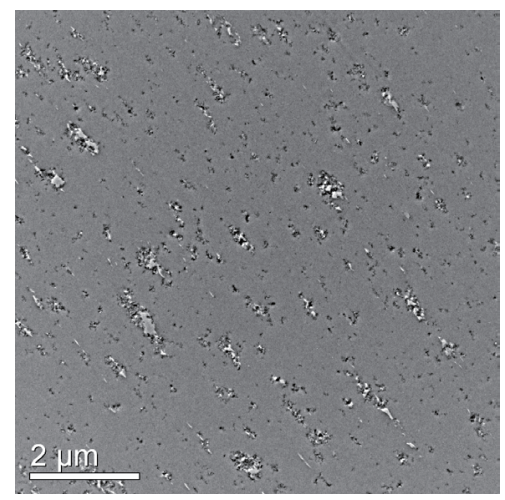

(a)

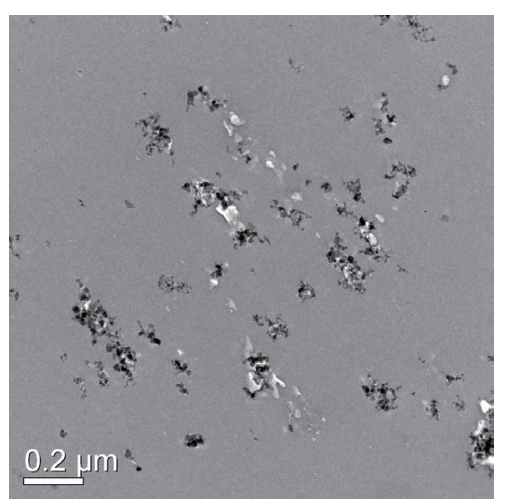

(c)

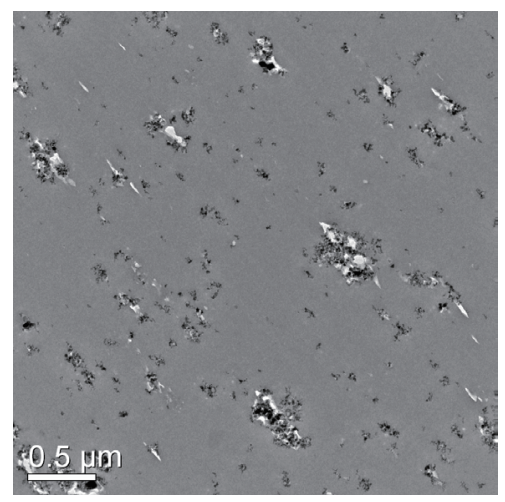

(b)

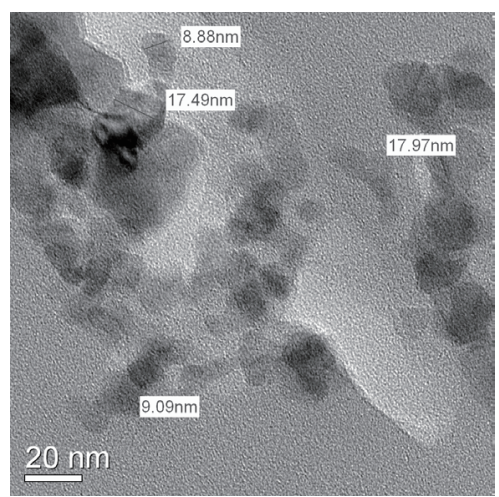

(d)

Fig. 4. TEM images of PANI-A1O3\% registered at different magnifications of (a) 2, (b) 10, (c) 100, and (d) 500k.

\subsection{Potentiodynamic measurements}

In this section, the anticorrosive performance of sample-coated SPCC electrodes was evaluated using OCP results, Tafel plots, and corrosion parameters, namely, the corrosion potential $\left(E_{c o r r}\right)$, linear polarization resistance $\left(R_{p}\right)$, corrosion current $\left(I_{\text {corr }}\right)$, and corrosion rate $\left(R_{\text {corr }}\right)$. The results of OCP measurements are shown in Fig. 5. The initial potentials of all the samples were unstable because the measured system was not in equilibrium in the first stage. After $30 \mathrm{~min}$ of OCP measurement, comparable potentials could be obtained because the system was near the equilibrium potential. Evidently, the potential curves of OCP obviously shifted toward a less negative potential range along with the ratio of gamma alumina, indicating that the effect of corrosion protection was greatly increased. Moreover, the PANI-A1O5\%-coated SPCC showed a marked drop in potential, indicating that the corrosion protection property of the coating seemed to obviously vary more than others, indicating that the $5 \mathrm{wt} \%$ load content of gamma alumina might reach the loading limit. Tafel plots for (a) uncoated, (b) PANI-coated, (c) PANI-A1O1\%coated, (d) PANI-AlO3\%-coated, and (e) PANI-A1O5\%-coated SPCC electrodes are shown in Fig. 6. The cathodic or anodic curves shifted to a less negative potential with lower current trends as 


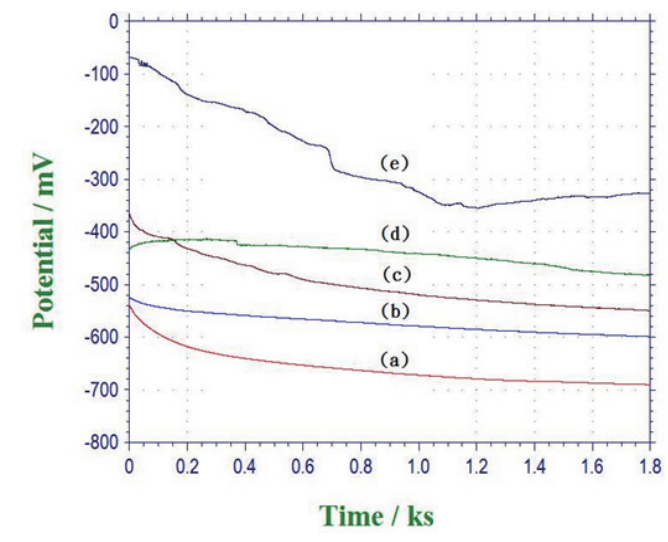

Fig. 5. (Color online) OCP curves of (a) uncoated (b) PANI-coated, (c) PANI-AlO1\%-coated, (d) PANIAlO3\%-coated, and (e) PANI-AlO5\%-coated SPCC electrodes measured in $5 \mathrm{wt} \%$ aqueous $\mathrm{NaCl}$ solution.

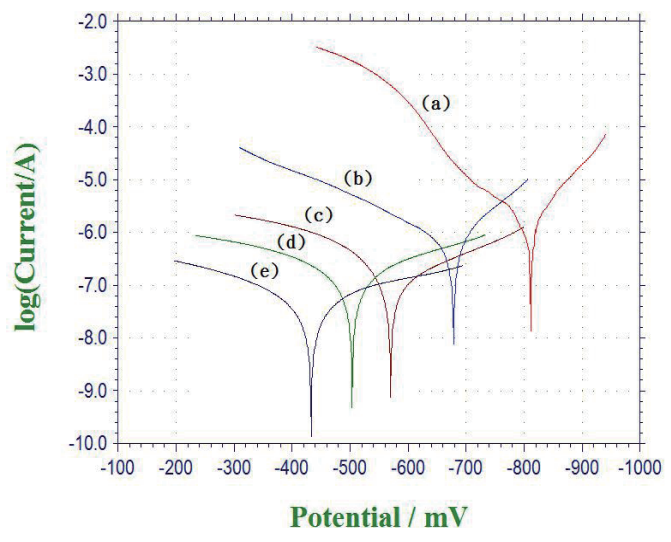

Fig. 6. (Color online) Tafel plots of (a) uncoated, (b) PANI-coated, (c) PANI-A1O1\%-coated, (d) PANI-AlO3\%-coated, and (e) PANI-A1O5\%-coated SPCC electrodes measured in $5 \mathrm{wt} \%$ aqueous $\mathrm{NaCl}$ solution.

the gamma-alumina load increased. The corrosion potential $\left(E_{c o r r}\right)$, polarization resistance $\left(R_{p}\right)$, corrosion current $\left(I_{\text {corr }}\right)$, and corrosion rate $\left(R_{\text {corr }}\right)$ were obtained and are summarized in Table 1. Generally, electrodes coated with PANI showed less negative $E_{c o r r}$, higher $R_{p}$, and lower $I_{c o r r}$ and $R_{\text {corr }}$ than the uncoated SPCC electrode. Furthermore, the anticorrosion performance increased with the load of gamma alumina, as observed in the corrosion data. The nanocomposite PANIAlO-coated sample exhibited a less negative corrosion potential and higher linear polarization resistance $\left(R_{p}\right)$ than the pure PANI-coated sample. The corrosion current $\left(I_{c o r r}\right)$ and corrosion rate $\left(R_{\text {corr }}\right)$ of the PANI-AlO-coated sample were also significantly lower than those of the PANIcoated sample. The corrosion rate of the PANI-A1O3\%-coated electrode was about 4.7 times lower than that of the PANI-coated electrode. The corrosion of the PANI-A1O5\%-coated electrode even become 14.4 times slower. This indicates that PANI-AlO nanocomposites exhibited better corrosion protection on SPCC electrodes than pure PANI. The protection efficiency $\left(P_{E F} \%\right)$ was estimated as ${ }^{(33)}$

$$
P_{E F} \%=100 \times\left[\left(R_{p}^{-1} \text { (uncoated) }-R_{p}^{-1}(\text { coated })\right] / R_{p}^{-1}\right. \text { (coated). }
$$

As expected, the corrosion resistance was significantly improved by using well-dispersed nanoparticles with the inert gamma alumina. The PANI-A1O5\% coating exhibited the highest $P_{E F} \%$ compared with pure PANI, as shown in Table 1 . The incorporation of nanoscale gamma alumina into PANI led to increased protection efficiencies of 8.6 (23.55/2.73), 10.8 (29.42/2.73), and $35.7(97.57 / 2.73)$ times for 1,3 , and 5\% gamma alumina, respectively.

\subsection{Electrochemical impedance measurements and mechanism of anticorrosion}

In this study, electrochemical impedance spectroscopy (EIS) was also used to evaluate the corrosion activity variation for the SPCC electrodes coated with PANI and PANI/A1O nanocomposite materials. The Nyquist plots are shown in Fig. 7. Two characteristic semicircles 


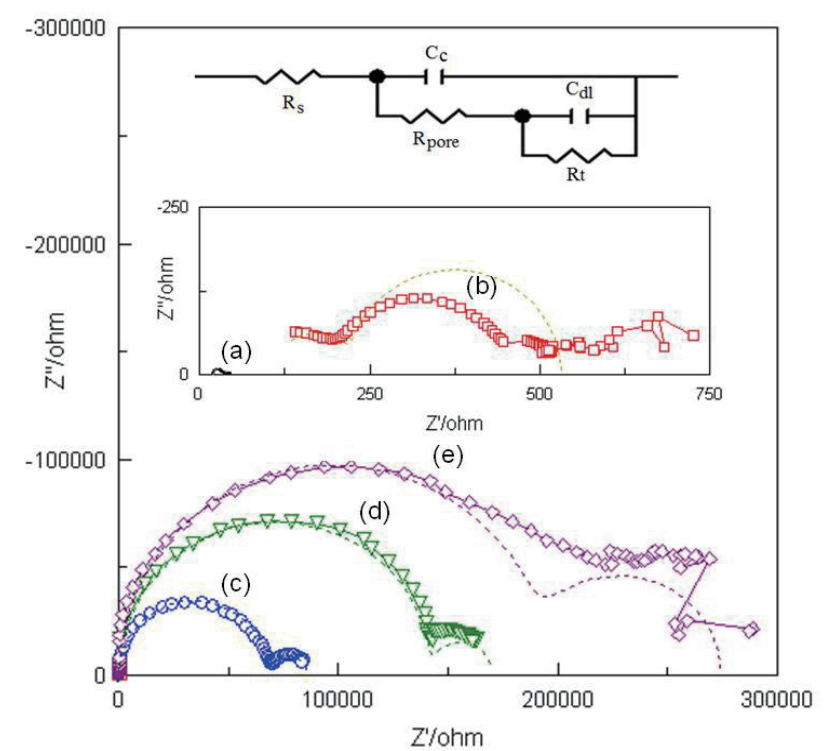

Fig. 7. (Color online) Equivalent circuit and Nyquist plots of (a) uncoated, (b) PANI-coated, (c) PANI-AlO1\%coated, (d) PANI-AlO3\%-coated, and (e) PANI-AlO5\%-coated SPCC electrodes measured in $5 \mathrm{wt} \%$ aqueous $\mathrm{NaCl}$ solution.

were observed, indicating two time constants in the Nyquist plots. The two characteristic semicircles gradually increased in diameter, indicating an increase in the total resistance of the coated SPCC electrodes with the addition of gamma alumina in the PANI matrix. The corrosion behavior was modeled with an equivalent circuit, as illustrated in Fig. 7, in which the circuit involves two sets of parallel capacitors and resistors in series along with solution resistance, where $R_{S}$ is the solution resistance, $C_{c}$ is the capacitance of the coating, $R_{\text {pore }}$ is the pore resistance of the coating, $R_{t}$ is the charge transfer resistance, of the coating substrate interface, and $C_{d l}$ is the doublelayer capacitance. All the parameters obtained from the simulated results of the equivalent circuit are listed in Table 1.

The capacitance $C_{c}$ depends on the surface area of the electrode, the thickness of the coating, and the properties of the dielectric. The relationship between the coating properties that affect $C c$ is $^{(34)}$

$$
C c=(\varepsilon)\left(\varepsilon_{o}\right)(A) / d,
$$

where $\varepsilon$ is the dielectric constant of the coating, $\varepsilon_{o}$ is $8.85 \times 10^{-14}$ Farads $/ \mathrm{cm}, A$ is the area $\left(\mathrm{cm}^{2}\right)$, and $d$ is the thickness $(\mathrm{cm})$. The $C c$ values of the nanocomposite coatings were slightly smaller than that of pure PANI, indicating that the dielectric property of the polymer might be enhanced by the incorporation of nanoscale gamma alumina into the polymer. The pore resistance $\left(R_{\text {pore }}\right)$ values extracted from the models greatly increased in the as-prepared nanocomposites compared with that of pure PANI, impliying that the resistance of electrolyte ions in the micropores of the metal greatly increased with the load of gamma alumina in the coating. The increase in the number of diffusion paths for the electrolyte ions might be due to dispersed alumina particles in the polymer matrix, as shown in Fig. 8. When loading a high content of gamma alumina, the 


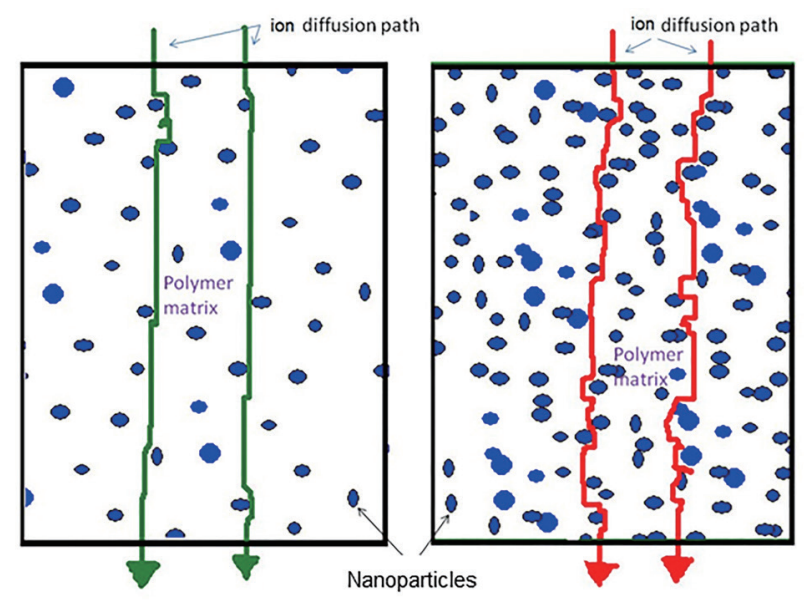

(a)

(b)

Fig. 8. (Color online) Proposed ion diffusion path for nanocomposites with (a) low and (b) high loads.

density of dispersed particles was expected to increase in the nanocomposites, and consequently, $R_{\text {pore }}$ increased. Furthermore, the dielectric property of the polymer might increase with the introduction of nanoscale gamma alumina, which might also reduce the ion conductivity and increase the coating resistance.

The double layer capacitance $\left(C_{d l}\right)$ of the polymer-coated SPCC electrode is slightly smaller than that of the bare SPCC electrode immersed in an electrolyte. $C_{d l}$ is in parallel with a kinetically controlled charge transfer resistance $\left(R_{t}\right)$. As shown in Table 1, a marked increase in the $R_{t}$ of the nanocomposite-coated SPCC was observed and compared with those of the pure PANI-coated and bare metal substrates. The results indicate that the incorporation of gamma alumina into the PANI matrix caused a higher charge transfer resistance than those in the PANI-coated and uncoated SPCC electrodes. Moreover, $R_{t}$ greatly increased with the content of nanoalumina, indicating a great improvement in the anticorrosion behavior. It should be further noted that PANI exhibited a low charge transfer resistance, i.e., $301 \Omega \cdot \mathrm{cm}^{2}$, while PANI-A1O5\% exhibited a great improvement in charge transfer resistance even up to $795 \mathrm{k} \Omega \cdot \mathrm{cm}^{2}$. This result clearly demonstrates that the sample with a high gamma-alumina content would have better corrosion protection performance. The improvement mechanism might be the same as previously discussed and shown in Fig. 8 for the increase in $R_{\text {pore }}$. Considering the surface of the metal substrate, SPCC, in contact with the $\mathrm{NaCl}$ electrolyte, the metal could electrolytically dissolve into the electrolyte during oxidation, wherein electrons enter the metal and metal ions diffuse into the electrolyte. Thus, charge was transferred during corrosion, and the diffusion pathway of metal ions in the nanocomposite matrix might also contribute to reducing the corrosion rate.

Furthermore, Bode plots were also studied for overall impedance comparison at different frequencies, as evidence of the effect of gamma alumina introduced into the polymer matrix. The Bode plots of the as-prepared sample-coated SPCC electrodes at different frequencies are shown in Fig. 9. The nanocomposite coating exhibited a higher impedance than pure PANI in the entire monitoring frequency range, according to the EIS Bode plots. The obvious increase in impedance at a high gamma-alumina content could be interpreted as being due to marked increases in the pore resistance $\left(R_{\text {pore }}\right)$ and charge transfer resistance $\left(R_{t}\right)$ of nanocomposites resulting from the presence 


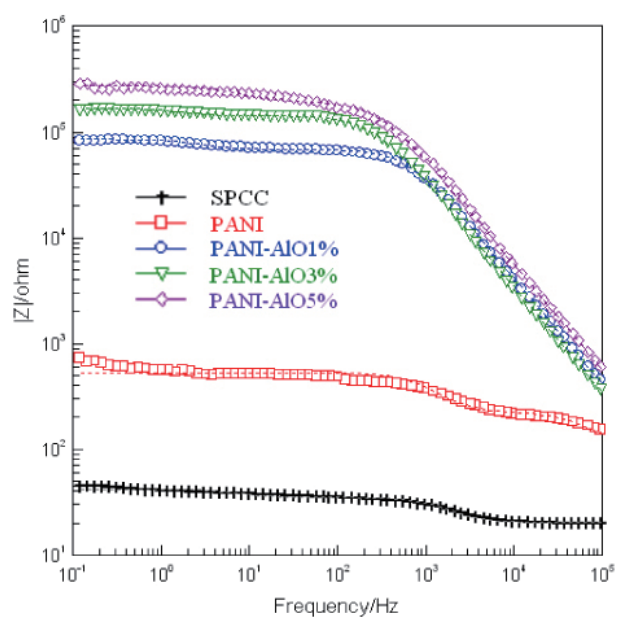

(a)

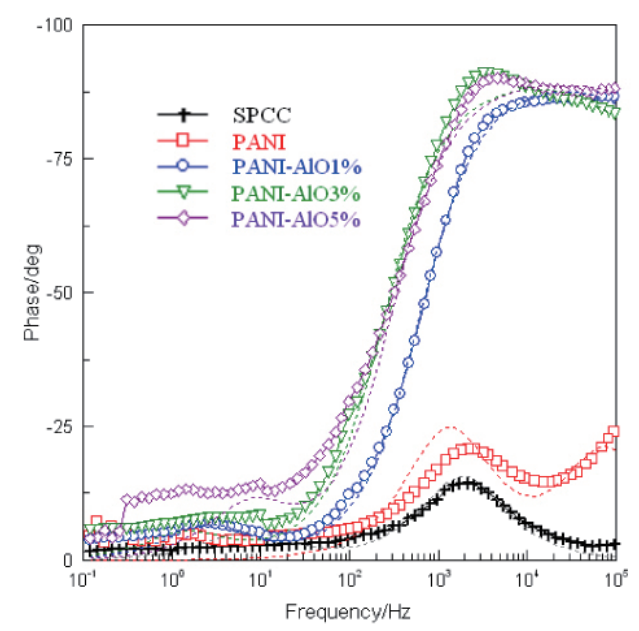

(b)

Fig. 9. (Color online) Bode plots of coated SPCC, measured in $5 \mathrm{wt} \%$ aqueous $\mathrm{NaCl}$ solution.

of nanoscale gamma alumina. The highly increased pore and charge transfer resistances resulted in Nyquist plots with two characteristic semicircles (i.e., as shown in Fig. 7), which are markedly different from those of the polyimide-clay-based system only fitted with a Randles circuit. ${ }^{(31)}$ Also, the corrosion potential $\left(E_{c o r r}\right)$ of the as-prepared nanocomposite coatings showed a greater shift to the anodic side than did that of the PANI-clay nanocomposite coatings. In this study, the $E_{\text {corr }}$ of PANI-alumina nanocomposites showed a shift of -0.68 to $-0.50 \mathrm{~V}$, while that of PANIclay nanocomposites showed a shift of -0.59 to $-0.54 \mathrm{~V}$, ${ }^{(24)}$ compared with those of pure PANI and $3 \mathrm{wt} \%$ nanocomposite materials. Therefore, as shown by electrochemical analyses, the enhanced corrosion effect might not be the only barrier effect in the nanoclay system. There has been no report in the past about the increase in the corrosion resistance of $\mathrm{PANI}_{-\mathrm{TiO}}{ }_{2}$ nanocomposites, ${ }^{(35)}$ which indicates a large shift of $E_{\text {corr }}$ for $\mathrm{PANI}-\mathrm{TiO}_{2}$ nanocomposites that explains the main mechanism in terms of the internal potential barrier arising from $\mathrm{TiO}_{2}$. Here, the gamma alumina used in this study might also act as a hindrance for hole transport and prevent the transport of metal ions during oxidation. In addition, as in our previous discussion, the dielectric property of the polymer might be increased by introducing nanoscale gamma alumina, which might also reduce the transport of metal ions. The enhanced anticorrosive effect for gamma-alumina PANI nanocomposite coatings compared with pure PANI might result from the physical barrier, potential barrier, and the dielectric effect of gamma-alumina particles; thus, the pore and charge transfer resistances markedly increased in this study.

\subsection{SEM observations of the effect of anticorrosion after corrosion test}

After the electrochemical measurement, the SPCC samples were stored in air for 2 months. The samples were used for the evaluation of the corrosive appearance of the surface of SPCC by SEM. We compared the nanocomposite-coated and back surfaces of the same measured sample without coating. The SEM observations of the surface morphology of SPCC after the corrosion test were compared between the uncoated and PANI-AlO3\%-coated substrates, as shown in Fig. 


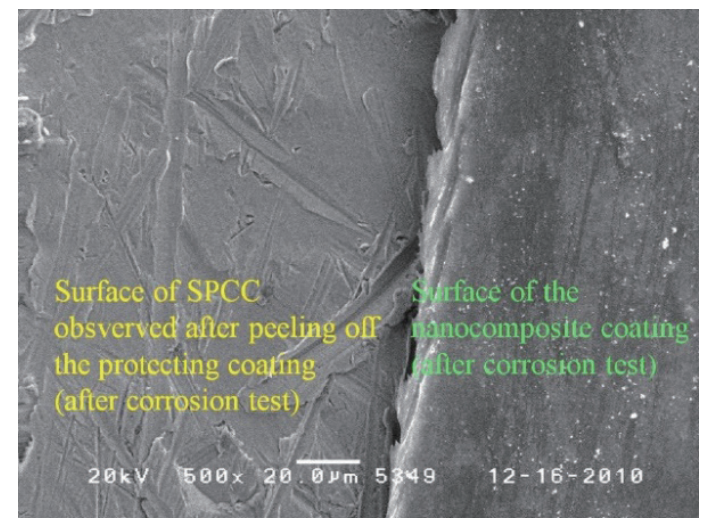

(a)

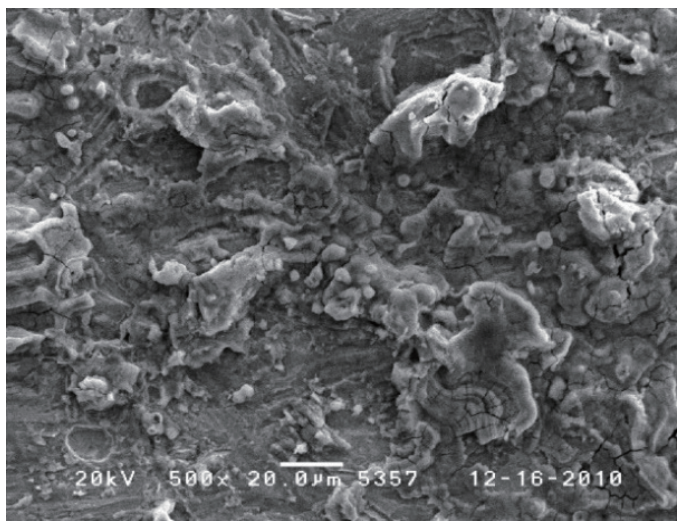

(b)

Fig. 10. (Color online) SEM images obtained after corrosion test. (a) SPCC coated with PANI-AlO3\% and (b) back of the same sample without coating, after sample was stored for two months.

10. After peeling off the nanocomposite coating from the SPCC surface, the visual observation of the surface still showed metallic luster; however, the back of the sample exhibited brownish oxide layers. The SEM images revealed that the SPCC surface was effectively protected by the as-prepared nanocomposite coatings, as shown in Fig. 10(a), in which the left side was the SPCC surface and the right side was the nanocomposite coating surface. As a result, we can only observe the polished pattern on the metal SPCC surface shown on the left side of Fig. 10(a); the back-side surface of the sample was covered with a layer of rust, as shown in Fig. 10(b). The observation was different from reported results that a passivation oxide layer was formed between the electroactive coating layer and the cold-rolled steel surface. ${ }^{(12,36)}$ The effect of corrosion inhibition could be clearly observed on the coating surface by visual or SEM analysis. Therefore, the corrosion inhibition of metal electrodes could effectively be improved by introducing nanocrystalline gamma alumina into the polymer matrix.

\section{Conclusions}

PANI-AlO nanocomposites were successfully prepared by the in situ ultrasonic dispersion of gamma-alumina particles followed by oxidative polymerization with the aniline monomer in an acidic solution. The structure of the as-prepared nanocomposites was characterized by ATRFTIR, XRD and HR-TEM. By a series of electrochemical analyses, the PANI-AlO nanocomposite coatings were found to exhibit effective corrosion protection on a cold-reduced carbon steel sheet. The potential curves of OCP showed trends shifting toward a less negative potential as a result of the addition of gamma alumina. The Tafel plot measurements indicated that $E_{\text {corr }}$ markedly shifted to a less negative potential, the polarization resistance increased, and the corrosion current decreased. The calculated corrosion rate of the PANI-A1O3\%-coated electrode was greatly improved to be 4.7 times lower than that of the PANI-coated electrode, and the corrosion of the PANI-A1O5\%-coated electrode even became 14.4 times slower. The protection efficiency (PEF\%) was calculated as $8.6,10.8$, and 35.7 times for 1,3 , and 5\% gamma alumina, respectively, compared with that of pure PANI. By EIS analyses, Nyquist plots were fitted with an equivalent circuit that 
presents two characteristic semicircles. All the parameters were obtained from the simulated results of the equivalent circuit and used for the evaluation of the anticorrosion effect of the PANIAlO nanocomposite coatings. The marked increase in pore resistance $\left(R_{\text {pore }}\right)$ indicates that gamma alumina could increase the resistance of the nanocomposite coatings. The marked increase in the charge transfer resistance $\left(R_{t}\right)$ of nanocomposites with the nanoalumina load clearly exhibited the effect of corrosion inhibition. Furthermore, increased $R_{\text {pore }}$ and $R_{t}$ led to a marked increase in total impedance, as shown in Bode plots. Finally, the mechanism of anticorrosion was proposed to be related to the physical barrier, potential barrier and dielectric effect of gamma-alumina particles. SEM observation also indicated the effectiveness of the as-prepared nanocomposite coatings for corrosion protection. All of these results indicate that PANI-AlO nanocomposites exhibit excellent corrosion protection on SPCC electrodes and can potentially inhibit corrosion.

\section{Acknowledgments}

The authors thank Taiwan Seed Improvement and Propagation Station (Contract 106B036-B) for financially supporting this research.

\section{References}

1 H. Shirakawa, E. J. Lousi, A. G. MacDiarmid, C. K. Chiang, and A. J. Heeger: J. Chem. Soc. Chem. Commun. 16 (1977) 578.

2 C. K. Chiang, C. R. Fincher, Y. W. Park, A. J. Heeger, H. Shirakawa, E. J. Lousi, S. C. Gau, and A. G. MacDiarmid: Phys. Rev. Lett. 39 (1997) 1098.

3 G. Gustafsson, Y. Cao, G. M. Treacy, F. Klavetter, N. Colaneri, and A. J. Heeger: Nature 357 (1992) 477.

4 J. H. Kang, Y. J. Oh, S. M. Paek, S. J. Hwang, and J. H. Choy: Sol. Energy Materi. Sol. Cells 93 (2009) 2040.

5 Z. Li, B. Ye, X. Hu, X. Ma, X. Zhang, and Y. Deng: Electrochem. Commun. 11 (2009) 1768.

6 L. Q. Hoa, Y. Sugano, H. Yoshikawa, M. Saito, and E. Tamiya: Biosens. Bioelectron. 25 (2010) 2509.

7 K. Brazdziuviene, I. Jureviciute, and A. Malinauskas: Electrochim. Acta 53 (2007) 785.

8 J. D. Sudha, S. Sivakala, R. Prasanth, V. L. Reena, and P. R. Nair: Compos. Sci. Technol. 69 (2009) 358.

9 Y. Gupta, K. Hellgardt, and R. J. Wakeman: J. Membr. Sci. 282 (2006) 60.

10 D. W. DeBerry: J. Electrochem. Soc. 132 (1985) 1022.

11 Y. Wei, J. Wang, X. Jia, J. M. Yeh, and P. Spellane: Polymer 36 (1995) 4535.

12 B. Wessling: Adv. Mater. 6 (1994) 226.

13 G. Spinks, A. Dominis, G. Wallace, and D. Tallman: J. Solid. State Electrochem. 6 (2002) 85.

14 W. S. Araujo, I. C. P. Margarit, M. Ferreira, O. R. Mattos, and L. P. Neto: Electrochim. Acta 46 (2001) 1307.

15 S. Qiu, C. Chen, W. Zheng, W. Li, H. Zhao, and L. Wang: Syn. Metals 229 (2017) 39.

16 S. Zhang, G. Sun, Y. He, R. Fu, Y. Gu, and S. Chen: ACS Appl. Mater. Interfaces 9 (2017) 16426.

17 R. Yuan, S. Wu, B. Wang, Z. Liu, L. Mu, T. Ji, L. Chen, B. Liu, H. Wang, and J. Zhu: Polymer 85 (2016) 37.

18 J. M. Yeh, S. J. Liou, C. Y. Lai, P. C. Wu, and C. Y. Tsai: Chem. Mater. 13 (2001) 1131.

19 J. M. Yeh, C. L. Chen, Y. C. Chen, C. Y. Ma, K. R. Lee, Y. Wei, and S. Li: Polymer 43 (2002) 2729.

20 Y. H. Yu, J. M. Yeh, S. J. Liou, and Y. P. Chang: Acta Mater. 52 (2004) 475.

21 J. M. Yeh, H. Y. Huang, C. L. Chen, W. F. Su, and Y. H. Yu: Surf. Coatings Technol. 200 (2006) 2753.

22 K. C. Chang, M. C. Lai, C. W. Peng, Y. T. Chen, J. M. Yeh, C. L. Lin, and J. C. Yang: Electrochim. Acta 51 (2006) 5645 .

23 K. C. Chang, G. W. Jang, C. W. Peng, C. Y. Lin, J. C. Shieh, J. M. Yeh, J. C. Yang, and W. T. Li: Electrochim. Acta 52 (2007) 5191.

24 K. C. Chang, H. F. Lin, C. Y. Lin, J. M. Yeh, J. C. Yang, and Y. H. Yu: J. Nanosci. Nanotechnol. 8 (2008) 3040.

25 K. C. Chang, S. T. Chen, H. F. Lin, C. Y. Lin, H. H. Huang, J. M. Yeh, and Y. H. Yu: Eur. Polym. J. 44 (2008) 13. 
26 K. C. Chang, H. H. Huang, M. C. Lai, C. B. Hung, B. Chand, J. M. Yeh, and Y. H. Yu: J. Nanosci. Nanotechnol. 9 (2009) 3125.

27 M. Bagherzadeh, H. Haddadi, and M. Iranpour: Prog. Org. Coat. 101 (2016) 149.

28 R. Yuan, S. Wu, H. Wang, L. Hu, Y. Zhu, S. Gao, Y. Zhu, and X. Zhang: J. Polym. Res. 24 (2017) 59.

29 J. Wu, S. Yang, S. Gao, A. Hu, J. Liu, and L. Fan: Eur. Polym. J. 41 (2005) 73.

30 D. H. Zhang: J. Appl. Polym. Sci. 101 (2006) 4372.

31 X. G. Li, M. R. Huang, J. F. Zeng, and M. F. Zhu: Colloids Surf., A. 248 (2004) 111.

32 JCPDS card, No. 29-0063.

33 J. Bockris and K. N. Reddy: Modern Electrochemistry (Plenum, New York, 1973).

34 D. Loveday, P. Peterson, and B. Rodgers: Evaluation of Organic Coatings with Electrochemical Impedance Spectroscopy Part 2: Application of EIS to Coatings. JCT Coatings Tech. 10 (2004) 88.

35 S. Radhakrishnan, C. R. Siju, D. Mahanta, S. Patil, and G. Madras: Electrochim. Acta 54 (2009) 1249.

36 K. Y. Huang, Y. S. Jhuo, P. S. Wu, C. H. Lin, Y. H. Yu, and J. M. Yeh: Eur. Polym. J. 45 (2009) 485.

\section{About the Authors}

Yuan-Fu Yu received his M.S. degree from HuaFan University, Taiwan, in 2010. His research interest is in materials.

Parthiban Venkatesan is currently a postdoctoral fellow in the Department of Chemistry at National Chung Hsing University, Taiwan.

Kuo-Yi Huang received his Ph.D. degree from National Chung Hsing University, Taiwan. Since 2013, he has been an associate professor at National Chung Hsing University, Taiwan. His research interests are in the area of machine vision and material. 